\title{
Prevalence of Nsaids (Non Steroidal Inflammatory Drugs) as a Chemopreventive Agent in Different Types of Cancer: Retrospective Detail Studies
}

\author{
Maria Ayub, Amna Islam \\ Jinnah University for Women, Karachi, Pakistan \\ Email: maria.ayub2000@gmail.com, amnaislam521@gmail.com \\ Received 10 August 2015; accepted 26 August 2015; published 31 August 2015 \\ Copyright (C) 2015 by authors and OALib. \\ This work is licensed under the Creative Commons Attribution International License (CC BY). \\ http://creativecommons.org/licenses/by/4.0/

(c) (i) Open Access

\begin{abstract}
NSAIDs are the most widely used drugs globaly and are very famous for their analgesic, anti-inflammatory and antipyretic actions. The use of NSAIDs in a variety of cancerous conditions is also approved now because of its versatile pharmacologic actions. In this research based study the use of NSAIDs as a chemointerceptive agent in a variety of cancers has been discussed. We aimed to know about the chemopreventive effects of NSAIDs that are a very diverse group of drugs having a lot of pharmacological actions. Now they are advised to prevent from various types of cancers by its different mechanisms and processes like inhibition of angiogenesis, COX-2 and it potentiates the process of apoptosis which is also a very favourable point for NSAIDs to work as a chemointerceptive agent. Heeding to the results aspirin could intercept from cancer $(37 \%)$ and other NSAIDs used as acheminterceptive agents (28\%). All of the NSAIDs have less side effects as compared to the drugs that are used during chemotherapy. The inhibition of COX-1 enzyme by NSAIDs is $(15 \%)$ and that of COX-2 (85\%). Studies suggested that the most frequent cancer in males is $14.5 \%$ of colorectal cancer and $10 \%$ prostate cancer while in female the most common cancers are $\mathbf{2 7 \%}$ of breast cancer and $15 \%$ of colorectal cancer. $30 \%$ of ovarian cancer is also very common in many females of elder age groups. It was concluded that NSAIDs are a diverse group of drugs and advised to manipulate as a chemointerceptive agents in a variety of cancers. Besides these studies there are many limitations heeding to the chronic usage of NSAIDs, which should also be considered. The use of NSAIDs as a chemointerceptive agent requires more further experimental studies and needs clinical trials.
\end{abstract}

\section{Keywords}

NSAIDs, Chemopreventiveuse, Chemopreventive Mechanism, Risk and Benefits of Aspirin, Other NSAIDs as Chemopreventive Agents

How to cite this paper: Ayub, M. and Islam, A. (2015) Prevalence of Nsaids (Non Steroidal Inflammatory Drugs) as a Chemopreventive Agent in Different Types of Cancer: Retrospective Detail Studies. Open Access Library Journal, 2: e1830. http://dx.doi.org/10.4236/oalib.1101830 


\section{Introduction}

NSAIDs (non steroidal anti inflammatory drugs) these are the most universal analgesic, anti inflammatory and antipyretic drugs using OTC (over the counter). From many decays it has been manipulated as an analgesic and anti inflammatory drug but now a variety of researches show that it can also intercept cancer. The most hugely used NSAIDs are aspirin (DISPIRIN), sulindec (CLINORIL), celecoxib (CELEBREX), piroxicam (FELDENE), acetaminophen (PARACETAMOL), Indomethacin (INDOCIN), nabumetone (RELAFEN) etc. The mechanism of action of NSAIDs is that it blocks the cycloxygenase pathways of arachidonic acid. The two sub forms of cycloxygenase that are cox 1 and cox 2 are blocked and inhibited by NSAIDs [1]-[7].

Aspirin is a very popular drug and has very well known irreversible antiplatelet activity. It is also used as anticoagulant and antipyretic (treat fever), anti inflammatory (treat inflammation) and analgesics (pain relief) actions. It is used to prevent from CHF chronic heart failure and stroke. It was previously delineated that chronic use of aspirin could prevent from ovarion cancer and colo rectal cancer by inhibiting its cancer prathological process. More special, those NSAIDs which block cox 2 pathway have more chemointerception activity. Adenomatous polyposis coli genes that are decreasing in cancerous cell can be recovered by NSAIDs. It has been reported that two most effective Nsaids Sulindac and celecoxib are effective in reducing angiogenesis of carcinoma and also effective against adenomatous polyps. The peak tolerated dose of Nsaids intercept cancer from $40 \%-60 \%$. In recent studies at the dose of 1500 (parts per minute in food) celicoxib intercept tumor progression $90 \%$ and the piroxicam at the dose of 25 (parts per minute in food) can reduce malignancy development $30 \%$. Both selective and non selective NSAIDs are delineated to intercept from cancer but when cancer treatment become prolonged the selective cox 2 Inhibitors are the associated choice. In root of habituation of cancer NSAIDs could safely ply for a long period of time with proper monitoring of clinical counselor. In healthy population NSAIDs prevent desist cancer $30 \%-50 \%$. Therefore aspirin is consuming as a interception of colorectal cancerous conditions. It was observed in innovatory studies that the patients taking aspirin once a week for 6 months or more have low risk of digestive route cancers [8]-[15].

Aspirin and other NSAIDs are also intercepted from cutaneous squamous cell carcinoma which is the common tumor of white citizenry. The major root of squamous cell carcinoma (SSC) is the frequent exposure to UV radiations which activate cyclooxygenase pathway and as a result prostaglandins formation occur hence NSAIDs have capability to block this cyclooxygenase pathway so it can eventually used as a chemopreventive agent in squamous cell carcinoma. It was also observed that a popular NSAID diclofenac if applied topicaly to the skin can prevent from skin tumor. NSAIDs could intercept peoples from skin cancer who have past history of keratinocyte tumor or vulnerable to malignancy [16]-[22]. NSAIDs are also delineated to treat gastric cancer. The second more global cancer is gastric cancer because chronic ulcer can lead to gastric tumor. The pathological process of gastric tumor is that when cox 2 is overexcited and there is less apoptosis in gastric it can lead to gastrinoma. NSAIDs are very well famous drugs to potentiate the processes of apoptosis and inhibit the cox pathway of arachidonic acid so it can absolutely be used as chemointerceptive agent. The prolonged chronic use of NSAIDs kept intercept from a variety of gastric malignencies. NSAIDs in prevention of gastric malignencies are dose dependent and also depend on duration of therapy. It's a well famous fact about NSAIDs that it is the major source of ulcer. In that illustration the patients with $H$. pylori supportive results can consume NSAIDs but $H$. pylori negative individuals who have low risk of ulcer and gastrinoma could use NSAIDs as a chemointerceptive agent. The non-selective NSAIDs are corresponding to more GIT toxicity so their use is prohibited as a chemopreventive agent in case of gastric cancer but, all the cox 2 selective inhibitors (for example: reficoxib, celecoxib, valdicoxib, etoricoxibetc) have less GIT toxicity so they should be used in both vulnerable and nonvulnerable citizenry [23]-[30].

NSAIDs are also proved to treat some of the gastrointestinal cancers especially colorectal cancer. It keeps also using to treat digestive cancers including Barrett's disease and pancreas tumor, the source is same as others that NSAIDs inhibit formation of prostaglandins and increase apoptosis which is very beneficial to treat cancer of all forms. While the gastro-intestinal tumors are the most common lethal and tumors [31]-[39]. NSAIDs are also delineated to reduce risk of breast cancer in fatty women. Obesity is the mainroot cause of breast cancer and 
now it becomes the most universal cancer globally. Women with overweight adipocytes infiltration of macrophages stimulate the COX-2 enzyme and prostaglandins release which cause stimulation of adipocyte aromatase which contribute excessive secretion of estrogen leading to breast cancer. NSAIDs reduce estrogen production and secretion by blocking estrogen receptor alpha and cyclooxygenase so it may reduce the risk of recurrent breast cancer in a preferable woman [40]-[45].

In the case of ovarian cancer NSAIDs could also manipulate as a chemointerceptive agent. Ovarian cancer is the most frequent lethal cancer of females. It was delineate that the females using aspirin, piroxicam naproxen and other NSIADs from decays have low risk of ovarian cancer. The Endometriosis of endometrium in ovaries and pelvic inflammatory disease (PID) is the major risk factor of ovarian cancer which can be overcomed by using non-steroidal anti-inflammatory drugs because they decrease the local inflammatory process going on into endometrium [46]-[48]. Prostate cancer, the most common visceral tumor of men, could also be intercepted by using NSAIDs because in prostate cancer over expression of cox, growth factors, cytokines and inflammatory mediators contribute which can be easily inhibited by using NSAIDs and it can also decrease the risk of androgen dependent and independent prostate cancer as well as benign (non-malignant cancer) hyperplasia [49]-[52].

The objective of these detailed studies is to evaluate chemoprotective role of Nsaids in different types of cancer from past studies in view of the fact to find out effective treatment option with proven role of Nsaids.

\section{Methodology}

This Retrospective Study was conducted in Karachi Last year 2014 in different oncology centers of confedential and private health care sectors of Pakistan. Now they are advised to seize from various types of cancers. This retrospective study represents data of chronically ill patient with immunocompromised system at oncology wards. During data collection especial emphasize done on the cancerous patients who me taken NSAIDs before or during therapy. Patients and prescribing pattern of different NSAIDs by physicians during therapy or before therapy was our main concern as irrational practice of Nsaids is very common in Pakistan [53] according to that studies aspirin can prevent from cancers (37\%) while other NSAIDs used as a chemopreventive agents (28\%). the ratio of various cancers interception by NSAIDs is: colorectal cancer (63\%), breast cancer (39\%), 36\% of lung cancer, $39 \%$ of prostate cancer, $73 \%$ esophageal cancer. $62 \%$ of stomach cancer and $47 \%$ of ovarian cancer. According to the guidance of world health organization (WHO) in 1986 the cancerous patients experience pain at all stages (59\%) during active therapy and 65\% during advance therapy while $70 \%$ - 80\% experience moderate to severe pain.

\section{Results}

Ratio between chemopreventive effects of aspirin and other NSAIDs describe as in Figure 1.

Table 1 shows some effective $\mathrm{COXi}_{\mathrm{bs}}$ with their mechanism of actions and aspirin associated risk \& benefits in Figure 2 respectively.

The cancer develop in an healthy individual by a staging system first preneoplasia then neoplasia occurs after that proper chemotherapy require to a patient as shown in Figure 3.

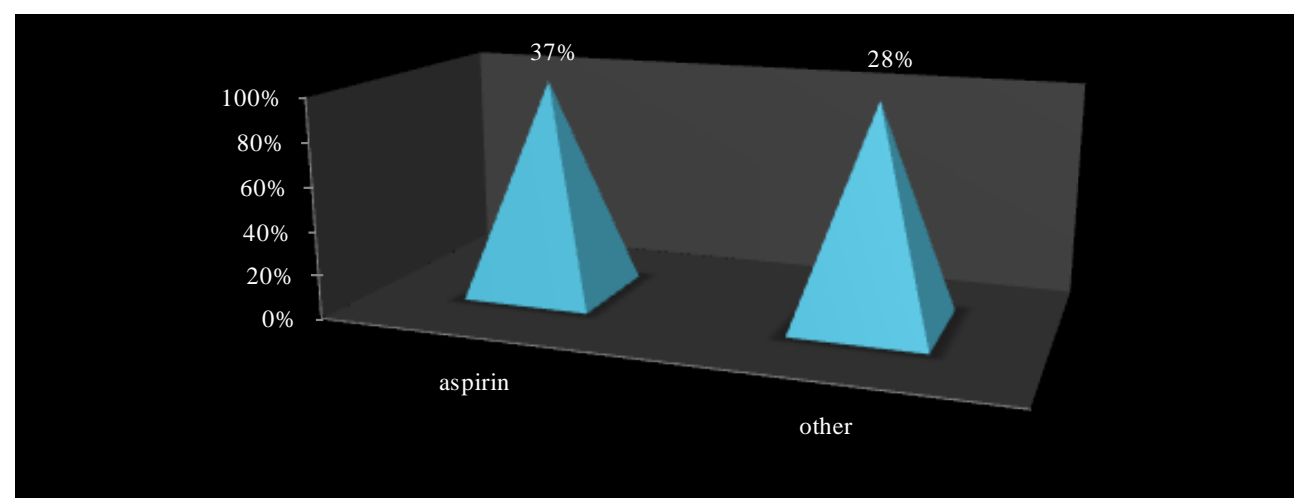

Figure 1. Ratio of chemopreventive effects of aspirin and other NSAIDs. 
Table 1. Therapeutic targets of different NSAIDs that is responsible for anticancer activity of agents (NSAIDs).

\begin{tabular}{|c|c|}
\hline Therapeutic target & Compound \\
\hline Cox-1/cox-2 inhibitors & $\begin{array}{c}\text { Piroxicam } \\
\text { Aspirin } \\
\text { Sulindec } \\
\text { Celecoxib (cox-2 only) }\end{array}$ \\
\hline Induction of apoptosis & $\begin{array}{l}\text { Piroxicam } \\
\text { Sulindec } \\
\text { aspirin }\end{array}$ \\
\hline Modulation of lipoxygenase & $\begin{array}{l}\text { Piroxicam } \\
\text { Aspirin } \\
\text { Sulindec }\end{array}$ \\
\hline Supprerssion of prostaglandin synthesis & $\begin{array}{l}\text { Piroxicam } \\
\text { Aspirin } \\
\text { Sulindec } \\
\text { Celecoxib }\end{array}$ \\
\hline Induction of cell cycle arrest & $\begin{array}{c}\text { Sulindec } \\
\text { Celecoxib }\end{array}$ \\
\hline Inhibition of angiogenesis & $\begin{array}{c}\text { Aspirin } \\
\text { celecoxib }\end{array}$ \\
\hline
\end{tabular}

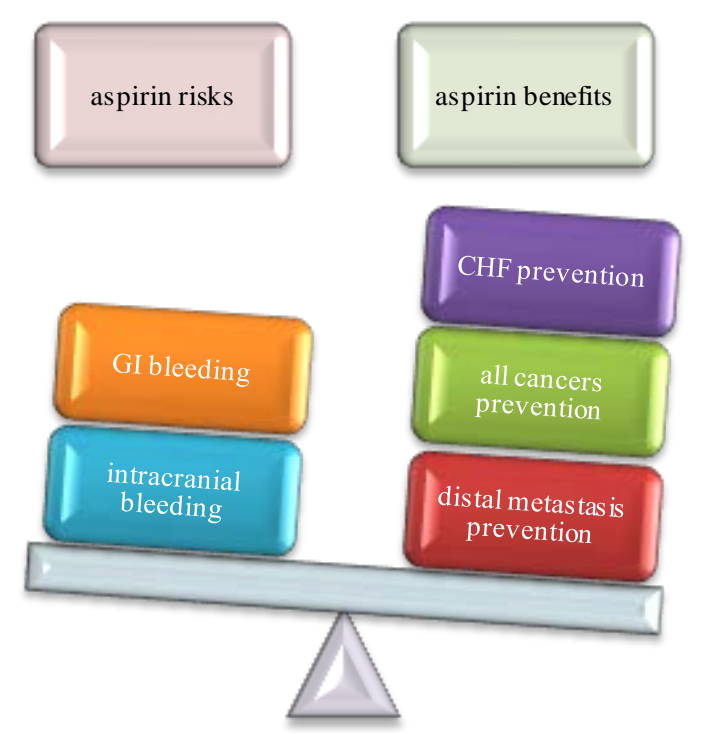

Figure 2. Risks and beneficial effects of aspirin over low doses.

The effects of chemopreventive agents in diet and in NSAIDs are described in Table 2.

The cox-2 enzyme (Table 3 ) is more frequently responsible for cancer and NSAIDs inhibition to cox-2 enzyme is a favourable point for a chemopreventive effects of NSAIDs as shown in Figure 4 and aspirin is proved to be most effective among all Nsaids (Figure 5) at various stages of pain in cancer (Figure 6).

The most common cancers occur in males and females, as shown in Figure 7 and Figure 8.

\section{Discussion}

NSAIDs (non steroidal anti-inflammatory drugs) are a diverse group of drug manipulated as an analgesic, antiinflammatory, antipyretic actions and a most universal OTC over the counter used drugs. Heeding to new innovatory studies NSAIDs could also used as a chemopreventive agent by its many mechanisms. Aspirin is a very famous NSAIDs and could use as a cancer preventive agent for a reason that it can recover back the adenomatous 


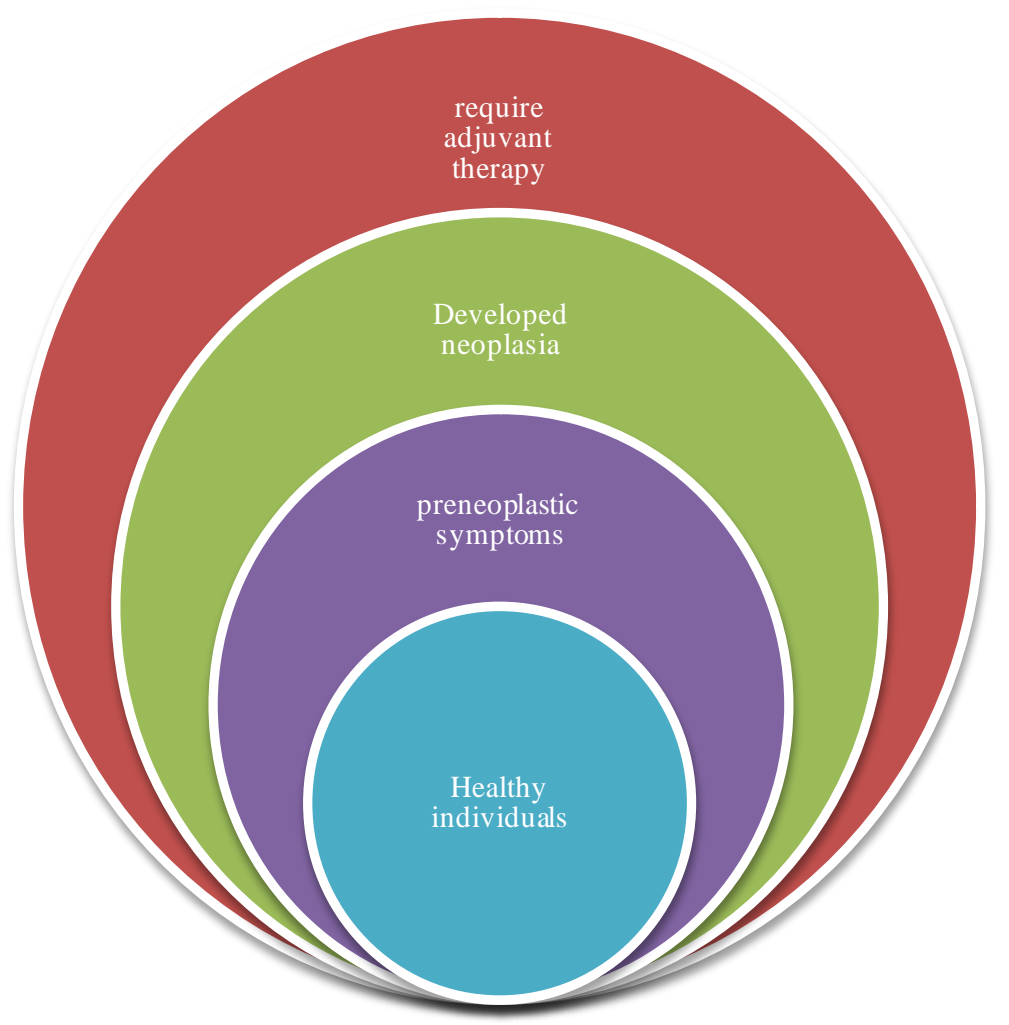

Figure 3. Stages of development of cancer in healthy individual.

Table 2. Comparison of chemopreventive NSAIDs with the agents present in our diet.

\begin{tabular}{cc}
\hline Agents & Effects \\
\hline Aspirin & Very effective \\
NSAIDs (ibuprofen, sulindec etc.) & Probably effective \\
Vitamin E, Vit. C and beta carotene & Not effective \\
Folate & Effective if mostly obtained in diet \\
Calcium & Effective almost \\
Estrogen & Effective but have other problems \\
Fiber & Not effective
\end{tabular}

Table 3. The actions of cyclooxygenase enzymes.

\begin{tabular}{cc} 
Action & Mechanism \\
\hline 1. Anti-inflammatory & COX-2 \\
2. Analgesic and anti-pyretic & COX-2 \\
3. Carcinoprotective & COX-2 \\
4. Anti-platelets & COX-1 (TXA2) \\
\hline
\end{tabular}




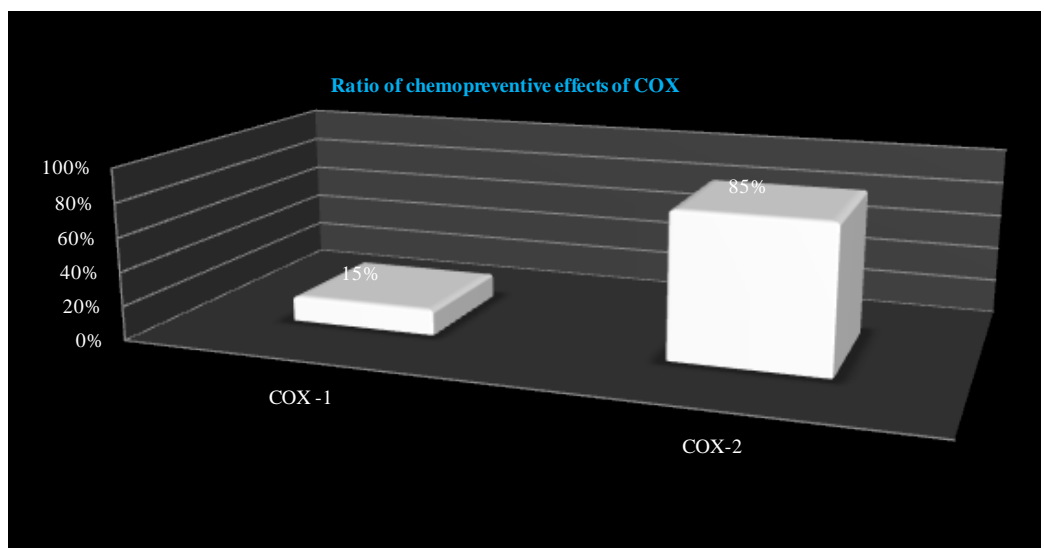

Figure 4. Ratio of cyclooxygenase enzyme blockade by NSAIDs to perform a chemoprotective action.

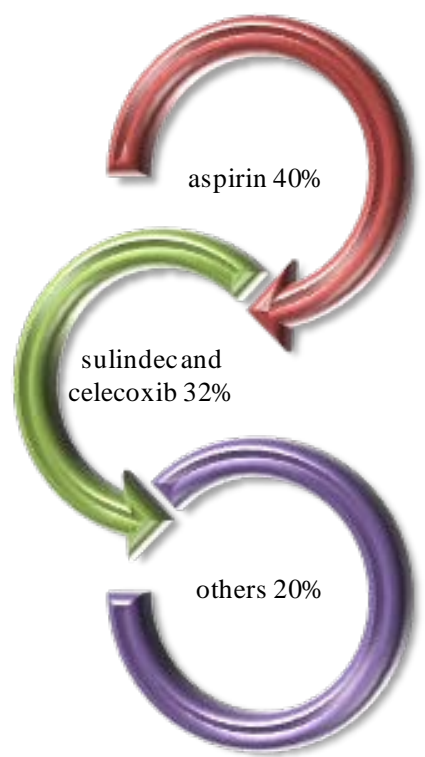

Figure 5. Frequency of prescribing ratio of NSAIDs as a chemopreventive agent.

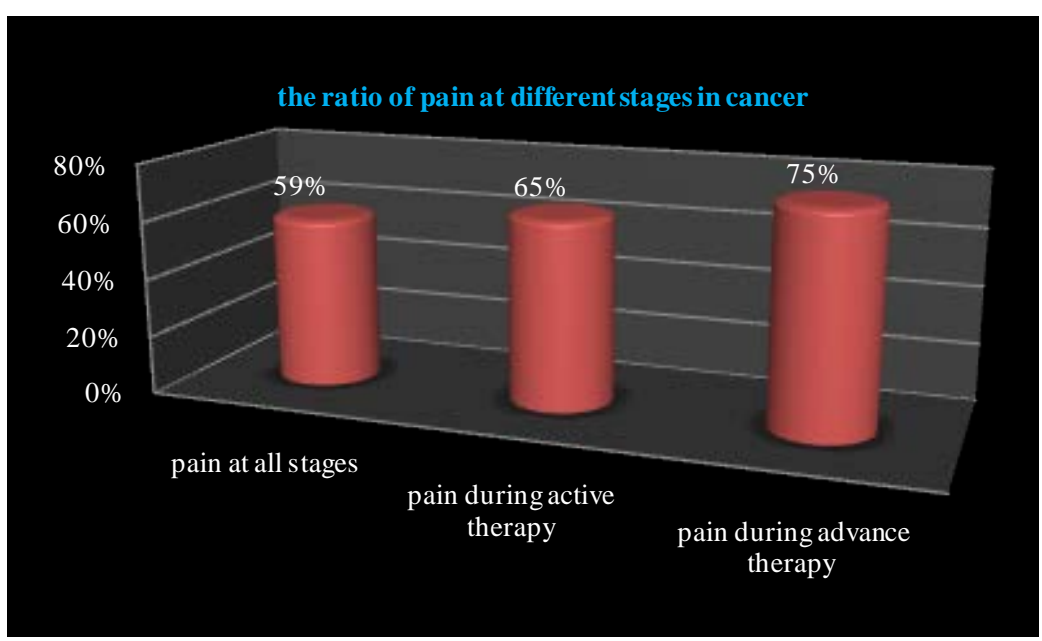

Figure 6. Frequency of pain in cancer patients during different stages. 


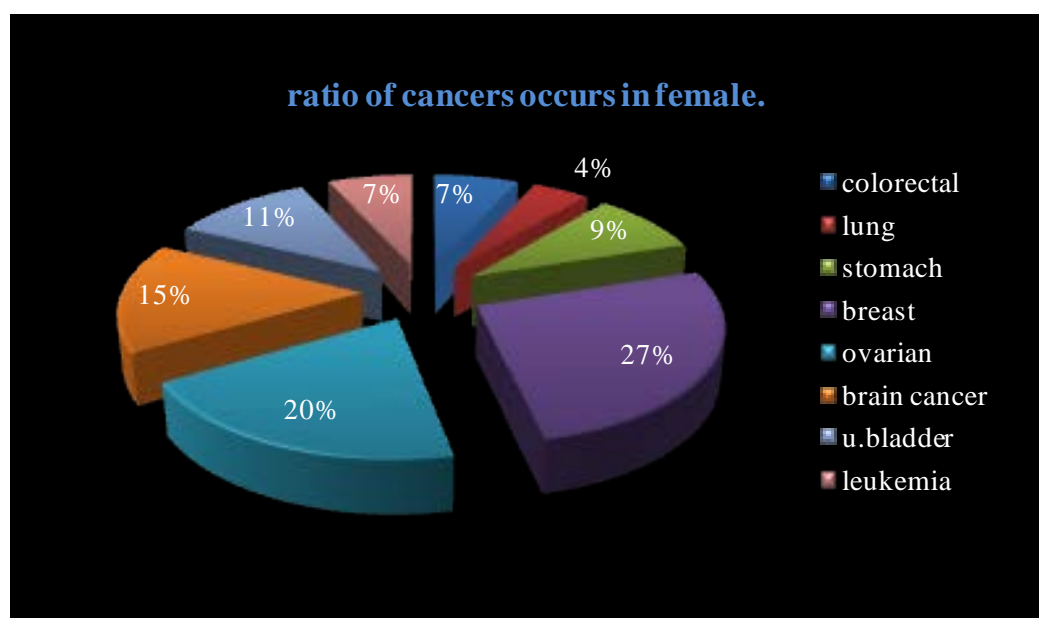

Figure 7. Ratio of common cancers occurs in female.

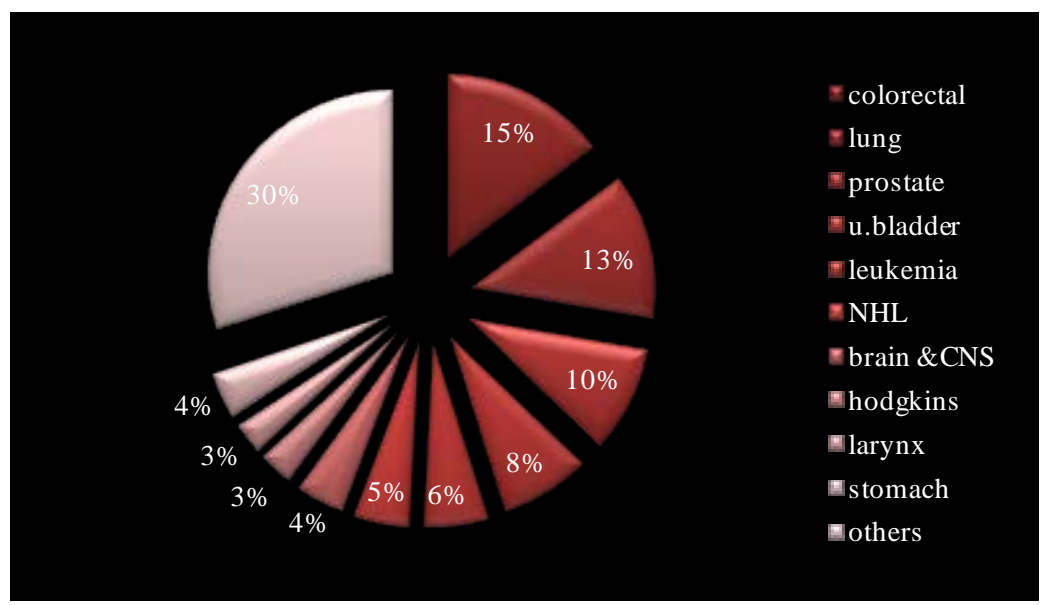

Figure 8. Sucesptiblity of most common cancers occurs in male.

polyposis coli gene which is lost during cancer also it inhibit the COX-2 enzyme which is responsible for its cancer interception effects. By inhibiting carcinogenesis aspirin delineated to treat a ovarian cancer and colorectal cancer. The two basic chemopreventive mechanism of NSAIDs are the inhibition of angiogenesis and stimulation of apoptosis. Topical application of diclofenac to the skin could prevent from skin cancer because of inhibition of COX-2 enzyme. The chronically usage of NSAIDs could intercept from a variety of gastric malignencies. the role of NSAIDs in prevention of gastric malignencies is dose dependent and also depends on duration of therapy. The $H$. pylori negative individual could use NSAIDs as a chemopreventive agent because chronic use of NSAIDs could cause GI bleeding. In an obese women the adipocytes infiltration macrophages overexcites the cox 2 enzyme due to this pro-inflammatory mediators PGs and ecosonoids are released which stimulate the adipocyte aromatase which eventually cause excess estrogen production that leads to breast cancer. NSAIDs decrease the estrogen secretion and block COX-2 enzyme hence used to intercept from breast cancer. COX-2 enzyme is more universal to treat cancers as compare to COX-1 enzyme. Colo-rectal cancer is the most global cancer worldwide which could be prevented by using aspirin. But the chronically use of aspirin could be a basic root of GI bleeding and intracranial bleeding so use of aspirin as a chemopreventive agent should be dose dependent and also depends on duration of therapy. Studies also delineated that NSAIDs can also prevent from most lethal cancer of females that is ovarian cancer due to its inhibition of inflammatory process ocuuring in endometriosis and could also intercept from pelvic inflammatory disease. The most eventually visceral cancer of males that is prostate cancer could also prevented by chronic use of NSAIDs. Shortly cancer is a lethal disease and its prevention is a very important point that could easily be done by using NSAIDs. 


\section{Conclusion}

It was concluded that NSAIDs could be used as a chemopreventive agent by different possible mechanism of actions. We have placed a basic stair which needs more research studies and should also be taken seriously by a observational and practical point of view. As cancer is a very well-known lethal disease condition and its prevention is very important for population and also for precancerous patients or the patients who are predisposed to any type of cancer. The chemopreventive features of NSAIDs in case of brain tumor are still not approved and require further observational and experimental studies. On the other hand of these limitations NSAIDs are very diverse and famous group of drugs which are most frequently used nowadays. Clinical trials are needed to further proceed and evaluate the chemopreventive use of NSAIDs in a medical sector. Therefore, strong studies also delineated that the same medication could also be used in other disease conditions like diabetes and hypertention but it requires further experimental studies.

\section{Disclosure \& Acknowledgements}

All of this work is unconditionally supported by the primary oncology centers of Pakistan. Authors are thankful to patients who share their experience and authors are heart fully thank full to the correspondence author MARIA AYUB for such a great assistance and providing a golden chance for this literature studies.

\section{Conflict of Interest}

Authors do not declare any conflict of interest regarding this publication.

\section{References}

[1] GLOBOCAN 2012 v1.0 (2013) Cancer Incidence and Mortality Worldwide: IARC CancerBase No. 11 [database on the Internet]. International Agency for Research on Cancer. http://globocan.iarc.fr

[2] Siegel, R., Ma, J., Zou, Z., et al. (2014) Cancer Statistics. CA: A Cancer Journal for Clinicians, 64, 9-29. http://dx.doi.org/10.3322/caac.21208

[3] Pohl, H. and Welch, H.G. (2005) The Role of Overdiagnosis and Reclassification in the Marked Increase of Esophageal Adenocarcinoma Incidence. Journal of the National Cancer Institute, 97, 142-146. http://dx.doi.org/10.1093/jnci/dji024

[4] Pohl, H., Sirovich, B. and Welch, H.G. (2010) Esophageal Adenocarcinoma Incidence: Are We Reaching the Peak? Cancer Epidemiology, Biomarkers \& Prevention, 19, 1468-1470. http://dx.doi.org/10.1158/1055-9965.EPI-10-0012

[5] Thrift, A.P. and Whiteman, D.C. (2012) The Incidence of Esophageal Adenocarcinoma Continues to Rise: Analysis of Period and Birth Cohort Effects on Recent Trends. Annals of Oncology, 23, 3155-3162. http://dx.doi.org/10.1093/annonc/mds181

[6] Vaughan, T.L. and Fitzgerald, R.C. (2015) Precision Prevention of Oesophageal Adenocarcinoma. Nature Reviews Gastroenterology \& Hepatology, 12, 243-248. http://dx.doi.org/10.1038/nrgastro.2015.24

[7] Engel, L.S., Chow, W.-H., Vaughan, T.L., et al. (2003) Population Attributable Risks of Esophageal and Gastric Cancers. Journal of the National Cancer Institute, 95, 1404-1413. http://dx.doi.org/10.1093/jnci/djg047

[8] Pandeya, N., Olsen, C.M. and Whiteman, D.C. (2013) Sex Differences in the Proportion of Esophageal Squamous Cell Carcinoma Cases Attributable to Tobacco Smoking and Alcohol Consumption. Cancer Epidemiology, 37, 579-584.

[9] Howlader, N., Noone, A., Krapcho, M., et al. (2014) SEER Cancer Statistics Review, 1975-2011. National Cancer Institute. Bethesda, MD. (Based on November 2013 SEER data submission, posted to the SEER web site, April 2014) http://seer.cancer.gov/csr/1975_2011/

[10] Cook, M.B., Chow, W.H. and Devesa, S.S. (2009) Oesophageal Cancer Incidence in the United States by Race, Sex, and Histologic Type, 1977-2005. British Journal of Cancer, 101, 855-859. http://dx.doi.org/10.1038/sj.bjc.6605246

[11] Dubecz, A., Gall, I., Solymosi, N., Schweigert, M., Peters, J.H., Feith, M. and Stein, H.J. (2012) Temporal Trends in Long-Term Survival and Cure Rates in Esophageal Cancer: A SEER Database Analysis. Journal of Thoracic Oncology, 7, 443-447. http://dx.doi.org/10.1097/jto.0b013e3182397751

[12] Spechler, S.J. (2002) Clinical Practice. Barrett’s Esophagus. The New England Journal of Medicine, 346, 836-842. http://dx.doi.org/10.1056/NEJMcp012118

[13] Ronkainen, J., Aro, P., Storskrubb, T., Johansson, S.E., Lind, T., Bolling-Sternevald, E., et al. (2005) Prevalence of Barrett's Esophagus in the General Population: An Endoscopic Study. Gastroenterology, 129, 1825-1831. http://dx.doi.org/10.1053/j.gastro.2005.08.053 
[14] Kendall, B.J. and Whiteman, D.C. (2006) Temporal Changes in the Endoscopic Frequency of New Cases of Barrett’s Esophagus in an Australian Health Region. The American Journal of Gastroenterology, 101, 1178-1182. http://dx.doi.org/10.1111/j.1572-0241.2006.00548.x

[15] Krishnan, K., Ruffin IV, M.T. and Brenner, D.E. (2000) Chemoprevention for Colorectal Cancer. Critical Reviews in Oncology/Hematology, 33, 199-219. http://dx.doi.org/10.1016/S1040-8428(99)00075-X

[16] Shiff, J.S. and Rigas, B. (1997) Nonsteroidal Anti-Inflammatory Drugs and Colorectal Cancer: Evolving Concepts of Their Chemopreventive Actions. Gastroenterology, 113, 1992-1998. http://dx.doi.org/10.1016/S0016-5085(97)99999-6

[17] Shiff, J.S. and Rigas, B. (1999) The Role of Cyclooxygenase Inhibition in the Antineoplastic Effects of Nonsteroidal Anti-Inflammatory Drugs. The Journal of Experimental Medicine, 190, 445-450. http://dx.doi.org/10.1084/jem.190.4.445

[18] Hardman, J.G., Limbert, L.E., Molinoff, P.B., Ruddon, R.W. and Gilman, A.G., Eds. (1996) Goodman and Gilman’s the Pharmacological Basis of Therapeutics. 9th Edition, McGraw-Hill, Inc., New York.

[19] Bjorkman, D.J. (1999) Current Status of Nonsteroidal Anti-Inflammatory Drug (NSAID) Use in the United States: Risk Factors and Frequency of Complications. American Journal of Medicine, 107, 3S-8S.

[20] Del Soldato, P., Sorrentino, R. and Pinto, A. (1999) NO-Aspirins: A Class of New Anti-Inflammatory and Antithrombotic Agents. Trends in Pharmacological Sciences, 20, 319-323. http://dx.doi.org/10.1016/S0165-6147(99)01353-X

[21] Wolfe, M.M. (1998) Future Trends in the Development of Safer Nonsteroidal Anti-Inflammatory Drugs. American Journal of Medicine, 105, 44S-52S. http://dx.doi.org/10.1016/S0002-9343(98)00281-2

[22] Fiorucci, S., Antonelli, E., Santucci, L., Morelli, O., Miglietti, M., Federici, B., Mannucci, R., Del Soldato, P. and Morelli, A. (1999) Gastrointestinal Safety of Nitric Oxide-Derived Aspirin Is Related to Inhibition of ICE-Like Cysteine Proteases in Rats. Gastroenterology, 116, 1089-1106. http://dx.doi.org/10.1016/S0016-5085(99)70012-0

[23] Qiao, L., Hanif, R., Sphicas, E., Shiff, S.J. and Rigas, B. (1998) Effect of Aspirin on Induction of Apoptosis in HT-29 Human Colon Adenocarcinoma Cells. Biochemical Pharmacology, 55, 53-64. http://dx.doi.org/10.1016/S0006-2952(97)00400-0

[24] Shiff, S.J., Koutsos, M.I., Qiao, L. and Rigas, B. (1996) Nonsteroidal Anti-Inflammatory Drugs Inhibit the Proliferation of Colon Adenocarcinoma Cells: Effects on Cell Cycle and Apoptosis. Experimental Cell Research, 222, 179-188. http://dx.doi.org/10.1006/excr.1996.0023

[25] Hanif, R., Feng, J., Shiff, S.J., Koutsos, M.I., Staiano-Coico, L. and Rigas, B. (1996) NSAIDs Inhibit the Growth of Colon Cancer Cells by a Prostaglandin-Independent Pathway. Biochemical Pharmacology, 52, 237-245. http://dx.doi.org/10.1016/0006-2952(96)00181-5

[26] Rigas, B. and Shiff, S.J. (2000) Is an Effect on Cyclooxygenase Required for the Chemopreventive Effect of NSAIDs in Colon Cancer? A Model Reconciling the Current Contradiction. Medical Hypotheses, 54, 210-215. http://dx.doi.org/10.1054/mehy.1999.0023

[27] Bakm, A.W., McKnight, W., Li, P., Del Soldato, P., Calignano, A., Cirino, G. and Wallace, J.L. (1998) Cyclooxygenase-Independent Chemoprevention with an Aspirin Derivative in a Rat Model of Colonic Adenocarcinoma. Life Sciences, 62, 367-373. http://dx.doi.org/10.1016/S0024-3205(98)00191-X

[28] Garcia-Rodriguez, L.A. and Huerta-Alvarez, C. (2001) Reduced Risk of Colorectal Cancer among Long-Term Users of Aspirin and Non-Aspirin Nonsteroidal Anti-Inflammatory Drugs. Epidemiology, 12, 88-93. http://dx.doi.org/10.1097/00001648-200101000-00015

[29] Rosenberg, L., Palmer, J.R., Zauber, A.G., Warshauer, M.E., Stolley, P.D. and Shapiro, S. (1991) A Hypothesis: Nonsteroidal Anti-Inflammatory Drugs Reduce the Incidence of Large Bowel Cancer. Journal of the National Cancer Institute, 83, 355-358. http://dx.doi.org/10.1093/jnci/83.5.355

[30] Rosenberg, L., Louik, C. and Shapiro, S. (1998) Nonsteroidal Anti-Inflammatory Drug Use and Reduced Risk of Large Bowel Carcinoma. Cancer, 82, 2326-2333. http://dx.doi.org/10.1002/(SICI)1097-0142(19980615)82:12<2326::AID-CNCR5>3.0.CO;2-Q

[31] Giovannucci, E., Rim, E.B., Stampfer, M.J., Colditz, G.A., Ascherio, A. and Willett, W.C. (1994) Aspirin Use and the Risk of Colorectal Cancer and Adenoma in Male Health Professionals. Annals of Internal Medicine, 121, 241-246. http://dx.doi.org/10.7326/0003-4819-121-4-199408150-00001

[32] Giovannucci, E., Egan, K., Hunter, D.J., Stampfer, M.J., Colditz, G.A., Ascherio, A., Willett, W.C. and Speizer, F.E. (1995) Aspirin and the Risk of Colorectal Cancer in Women. The New England Journal of Medicine, 333, 609-614. http://dx.doi.org/10.1056/NEJM199509073331001

[33] Berkel, H.J., Holcombe, R.F., Middlebrooks, M. and Kannan, K. (1996) Nonsteroidal Anti-Inflammatory Drugs and Colorectal Cancer. Epidemiologic Reviews, 18, 205-217. http://dx.doi.org/10.1093/oxfordjournals.epirev.a017926 
[34] Thun, M.J., Namboodiri, M.M. and Heath Jr., C.W. (1991) Aspirin Use and Reduced Risk of Fatal Colon Cancer. The New England Journal of Medicine, 325, 1593-1596. http://dx.doi.org/10.1056/NEJM199112053252301

[35] Muscat, J.E., Stellman, S.D. and Wynder, E.L. (1994) Nonsteroidal Anti-Inflammatory Drugs and Colorectal Cancer. Cancer, 74, 1847-1854.

[36] Pollard, M. and Luckert, P.H. (1980) Indomethacin Treatment of Rats with Dimethylhydrazine-Induced Intestinal Tumors. Cancer Treatment Reviews, 64, 1323-1327.

[37] Pollard, M. and Luckert, P.H. (1984) Effect of Piroxicam on Primary Intestinal Tumors Induced in Rats by N-Methylnitrosourea. Cancer Letters, 25, 117-121. http://dx.doi.org/10.1016/S0304-3835(84)80035-X

[38] Metzger, U., Meier, J., Uhlshmid, G. and Weihe, H. (1984) Influence of Various Prostaglandin Synthesis Inhibitors on DMH-Induced Rat Colon Cancer. Diseases of the Colon \& Rectum, 27, 366-369. http://dx.doi.org/10.1007/BF02553001

[39] Reddy, B.S., Maruyama, H. and Kelloff, G. (1987) Dose-Related Inhibition of Dietary Piroxicam, a Nonsteroidal AntiInflammatory Drug, during Different Stages of Rat Colon Tumor Development. Cancer Research, 47, 5340-5346.

[40] Reddy, B.S., Nayini, J., Tokumo, K., Rigotty, J., Zang, E. and Kelloff, G. (1990) Chemoprevention of Colon Carcinogenesis by Concurrent Administration of Piroxicam, a Nonsteroidal Anti-Inflammatory Drug with D,L-a-diftuoromethylornithine, an Ornithine Decarboxylase Inhibitor, in Diet. Cancer Research, 50, 2562-2568.

[41] Rubio, C.A. (1984) Antitumoral Activity of Indomethacin on Experimental Esophageal Tumors. Journal of the National Cancer Institute, 72, 705-707.

[42] Takahashi, M., Furukawa, F., Toyoda, K., Sato, H., Hasegawa, R., Imaida, K. and Hayashi, Y. (1990) Effects of Various Prostaglandin Synthesis Inhibitors on Pancreatic carcinogenesis in Hamsters after Initiation with $\mathrm{N}$-Nitrosobis(2oxopropyl)amine. Carcinogenesis, 11, 393-395. http://dx.doi.org/10.1093/carcin/11.3.393

[43] Tanaka, T., Kojima, T., Okumura, A., Sugie, S. and Mori, H. (1993) Inhibitory Effect of the Non-Steroidal AntiInflammatory Drugs, Indomethacin and Piroxicam on 2-Acetylaminofluorene-Induced Hepatocarcinogenesis in Male ACI/N Rats. Cancer Letters, 68, 111-118. http://dx.doi.org/10.1016/0304-3835(93)90136-W

[44] Jalbert, G. and Castonguay, A. (1992) Effects of NSAIDs on NNK-Induced Pulmonary and Gastric Tumorigenesis in A/J Mice. Cancer Letters, 66, 21-28. http://dx.doi.org/10.1016/0304-3835(92)90275-Z

[45] Thun, M.S., Namboodiri, M.M., Calle, E.E., Flanders, M.D. and Heath Jr., C.W. (1993) Aspirin Use and Risk of Fatal Cancer. Cancer Letters, 53, 1322-1327.

[46] Gridley, G., McLaughlin, J.K., Ekbom, A., Klareskog, L., Adami, H.O., Hacker, D.G., Hoover, R. and Fraumeni, J.F. (1993) Incidence of Cancer among Patients with Rheumatoid Arthritis. Journal of the National Cancer Institute, 85, 307-311. http://dx.doi.org/10.1093/jnci/85.4.307

[47] Funkhouser, E.M. and Sharp, G.B. (1995) Aspirin and Reduced Risk of Esophageal Carcinoma. Cancer, 76, 11161119. http://dx.doi.org/10.1002/1097-0142(19951001)76:7<1116::AID-CNCR2820760703>3.0.CO;2-I

[48] Farrow, D.C., Vaughan, T.L., Hansten, P.D., Stanford, J.L., Risch, H.A., Gammon, M.D., Chow, W.H., Dubrow, R., Ahsan, H., Mayne, S.T., Schoenberg, J.B., West, A.B., Rotterdam, H., Fraumeni Jr., J.F. and Blot, W.J. (1998) Use of Aspirin and Other Nonsteroidal Anti-Inflammatory Drugs and Risk of Esophageal and Gastric Cancer. Cancer Epidemiology, Biomarkers \& Prevention, 7, 97-102.

[49] Shapiro, S. (1982) Case-Control Surveillance. In: Strom, B.L., Ed., Pharmacoepidemiology, 2nd Edition, John Wiley and Sons, Chichester, 301-322.

[50] Schreinemachers, D.M. and Everson, R.B. (1994) Aspirin Use and Lung, Colon, and Breast Cancer Incidence in a Prospective Study. Epidemiology, 5, 138-146.

[51] World Health Organization (2012) World Health Statistics 2012. http://www.who.int/gho/publications/world_health_statistics/2012/en/

[52] Flegal, K.M., Carroll, M.D., Kit, B.K. and Ogden, C.L. (2012) Prevalence of Obesity and Trends in the Distribution of Body Mass Index among US Adults, 1999-2010. The Journal of the American Medical Association, 307, 491-497. http://dx.doi.org/10.1001/jama.2012.39

[53] Calle, E.E., Rodriguez, C., Walker-Thurmond, K. and Thun, M.J. (2003) Overweight, Obesity, and Mortality from Cancer in a Prospectively Studied Cohort of US Adults. The New England Journal of Medicine, 348, 1625-1638. http://dx.doi.org/10.1056/NEJMoa021423 


\section{Abbreviations}

COX-1\& 2: cyclooxygenase 1 \& 2;

TAX-A2: thromboxane A2;

FAP: familial adenomatous polyposis;

SCC: squamous cell carcinoma;

PID: pelvic inflammatory disease. 